\title{
Study of Structure Oscillations Under One-component Kinematic Effect
}

\author{
Fakhriddin Bekchanov, Rustam Ergashev and Mirziyod Mirsaidov* \\ Tashkent Institute of Irrigation and Agricultural Mechanization Engineers, Uzbekistan
}

Submission: October 12, 2018; Published: November 14, 2018

*Corresponding author: Mirziyod Mirsaidov, Department of Theoretical and Structural Mechanics, Tashkent Institute of Irrigation and Agricultural Mechanization Engineers, Uzbekistan

\begin{abstract}
Mathematical statement, methods and algorithm to solve the problem of steady-state forced vibrations of a structure are given in the paper using spatial model with account of viscoelastic properties of material of various structures and their elements under one-component kinematic effect. The results of study of earth structure oscillations under one-component kinematic effect are presented.

It is stated that:

A. for the structures under consideration in dynamic calculations it is desirable to use a spatial model;

B. viscoelastic properties of soil under the load effect slightly reduce the amplitude of oscillations, and after effect cessation these properties lead to a sharp attenuation of structure oscillations.
\end{abstract}

Keywords: Earth structure; One-component effect; Dynamic calculation; Resonance; Attenuation; Viscoelastic properties of soil; Plane and spatial models

\section{Introduction}

Studies have shown that for reliable investigation of structure and equipment oscillations, the possibility to use plane or spatial model depends mainly on the geometric parameters and inhomogeneous features of these objects and the nature of their strain under possible combinations of different loads. For example, when calculating various structures, only one component of seismic effect is taken into account in current regulatory documents on earthquake engineering. It is believed that the vertical acceleration is less than the horizontal one. However, engineering analysis of the aftermath of various earthquakes has shown the presence of some damage, the nature of which is difficult to explain by the action of horizontal component of seismic effect [1-3].

According to seism metricsss observations, it has been stated that at strong ground motion, along with the horizontal component of acceleration, other components of accelerations predominate [4-6]. To reliably assess the strength of a structure, it is necessary to answer the questions - when it is necessary to use plane or spatial model of structure and which components of the earthquake's accelerogram should be used as external effects.

In recent studies of structure oscillations, the use of a plane model of structure under one-component effect is mainly considered, and in rare cases two-component kinematic effect [716].
Therefore, in this paper an attempt is made to investigate the oscillations of various earth dams using the spatial model of a structure, taking into account viscoelastic properties of soil and the inhomogeneous features of a structure under one-component acceleration of an earthquake. To answer these questions when studying structure oscillations, it is necessary to consider the problem of determining the components of the displacement vector and the stress tensor with time arising at the points of the structure at different directions of non-stationary dynamic effects using a spatial model.

\section{Materials and Methods}

An inhomogeneous system is considered (Figure 1) in the paper; it consists of deformable bodies of volume $\mathrm{V}=\mathrm{V}_{1}+\mathrm{V}_{2}+\mathrm{V}_{3}$. The lower part of the system is located on a rigid base $S_{0^{\prime}}$ where a kinematic effect $\vec{u}_{0}\left(x_{1}, \tilde{o}_{2}, t\right)$ is applied. Hydrostatic pressure $\vec{\theta}_{s}$ $\left(x_{1}, \mathrm{x}_{2}\right)$ acts on $S_{p}$ part of the surface $S_{1}$, and the remaining part $\left(S_{2}\right.$, $S_{3}$ ) of the surface is stress free. The system (Figure 1) is a massive body, so the calculation takes into account mass forces $\vec{f}$. Material of different parts of the system is considered linearly elastic or viscoelastic. At the boundaries of the system regions (Figure 1) the displacements, the stress components are continuous.

The task is to determine the displacement and stress fields of the system (Figure 1), taking into account mass forces $\vec{f}$, water 
pressure $\vec{\bigoplus}_{s}\left(x_{1}, \mathrm{x}_{2}\right)$ and kinematic effect at the base $\vec{u}_{0}\left(x_{1}, \tilde{o}_{2}, t\right)$ . To state the problem, the principle of virtual displacements is used, according to which the sum of work of all active forces, including inertia forces, on virtual displacements is zero [17]:

$\delta A=-\int_{V} \sigma_{\ddot{y}} \delta{ }_{j} d-\int_{V} \rho_{n} \ddot{\ddot{u}} \delta \vec{u} d+\int_{V} \vec{f} \delta \ddot{u} d+\int_{S_{P}} \vec{p}_{\mathrm{s}} \delta \vec{u} \boldsymbol{\delta}=0$ (1)

Here $\vec{u}, \varepsilon_{i j}, \sigma_{i j}$ are the displacement vector and the components of the strain and stress tensors, respectively; $\delta \vec{u}, \delta \varepsilon_{i j}$ are isochronous variations of displacements and strains; $\rho_{n}$ is the density of material of the system elements; $\vec{f}$ is the mass force vector; $\vec{p}_{s}$ is hydrostatic pressure of water. Hereinafter, the index $n=1,2,3$ means the element of the system (i.e. the volume $\mathrm{V}$ ) the given mechanical characteristics refer to.

To describe the properties of viscoelastic material of the elements of the system (Figure 1), the heredity BoltzmannVolterra theory [18] is used, according to which the relations between the stress $\sigma_{j}$ and strain $\varepsilon_{j}$ tensors have the form $[18,19]$ :

$$
\varepsilon_{j}=\frac{1}{2}\left(\frac{\partial u_{i}}{\partial x_{j}}+\frac{\partial u_{j}}{\partial x_{i}}\right), i, j=1,2,3(4)
$$

To simulate the dynamic process in the system (Figure 1), kinematic conditions at the base are also set.

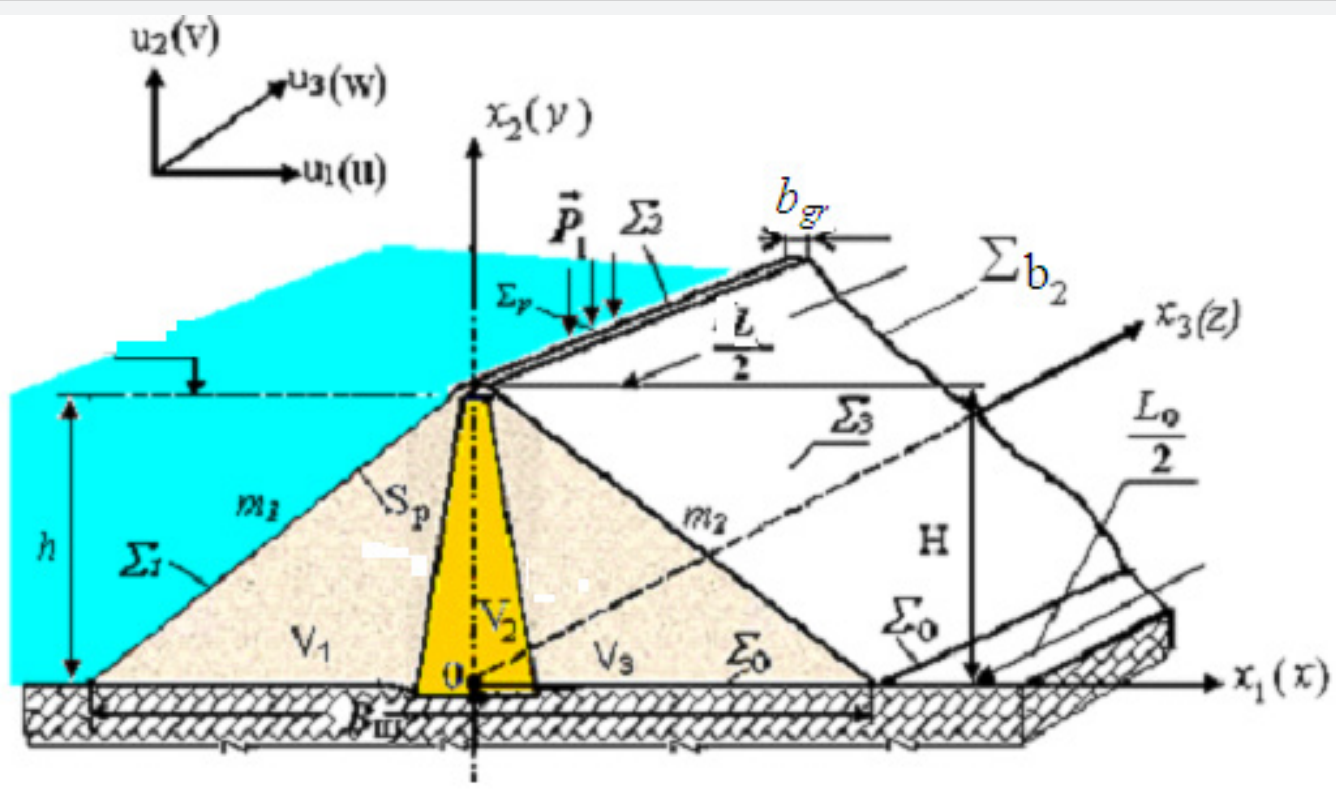

Figure 1: Inhomogeneous Deformable System.

$\vec{x} \in \Sigma_{0}: \vec{u}_{0}(\vec{x}, t)=\vec{\psi}_{1}(t),(5)$

boundary conditions at $t=0$ :

$\vec{x} \in V: \vec{u}(\vec{x}, 0)=\vec{\psi}_{2}(\vec{x}) \quad \dot{\vec{u}}(\vec{x}, 0)=\vec{\psi}_{3}(\vec{x}),(6)$

where $\vec{\psi}_{1}$ is the given function of time; $\vec{\psi}_{2}, \vec{\psi}_{3}$ are the given functions of coordinates. Displacement vector has three components $\vec{u}=\left\{u_{1}, u_{2}, u_{3}\right\}$ in the coordinate system $\vec{x}=\left\{x_{1}, x_{2}, x_{3}\right\}$ . Variation problem considered above using the procedure [20] of the finite elements method (with spatial finite elements) is reduced to a resolving system of integro-differential equations of large order, that is:

$[M]\{\ddot{u}(t)\}+\lceil C\rceil\{\dot{u}(t)\}+[K]\{u(t)\}=\{f(t)\}+\int_{0}^{t} \tilde{A}(t-\tau)[K]\{u(\tau)\} d \tau,(7)$

at initial conditions

$$
\{u(0)\}=\left\{u_{0}\right\},\{\dot{u}(0)\}=\left\{\mathrm{v}_{0}\right\} \text {. }
$$

Here, $[M],[K]$ are the matrices of mass and stiffness of the entire structure; $[C]$ is the matrix of dissipative forces, if internal friction is taken into account in structure material; $\{u(t)\}$ is the vector of sought for displacement amplitudes; $\{f(t)\}$ is the vector of external load from kinematic effect and hydrostatic pressure.
In assessment of the dynamics of considered dams, the order of solved systems of integro-differential equations reached 1700. Systems of integro-differential equations (7) with initial conditions (8) are solved by the Newmark method [20]. Using the procedure of the Newmark method, the system of integrodifferential equations (7) can be reduced to an algebraic system of equations

$$
\begin{aligned}
& {[A]\left\{u_{i+1}\right\}=\left\{R_{i+1}\right\} \text { (9) }} \\
& \text { where } \\
& {[A]=[K]+\frac{1}{\alpha \Delta t^{2}}[M]+\frac{\beta}{\alpha \Delta t}[C],(10)} \\
& \left\{R_{i+1}\right\}=\left\{f_{i+1}\right\}+[M]\left\{\frac{1}{\alpha \Delta t^{2}}\left\{u_{i}\right\}+\frac{1}{\alpha \Delta t}\left\{\dot{u}_{i}\right\}+\left(\frac{1}{2 \alpha}-1\right)\left\{\ddot{u}_{i}\right\}\right\}+ \\
& +[C]\left\{\frac{\beta}{\alpha \Delta t}\left\{u_{i}\right\}+\left(\frac{\beta}{\alpha}-1\right)\left\{\ddot{u}_{i}\right\}+\frac{\Delta t}{2}\left(\frac{\beta}{\alpha}-2\right)\left\{\ddot{u}_{i}\right\}\right\}+\left\{W_{i+1}\right\} \\
& \left\{W_{i+1}\right\}=\int_{0}^{t_{i+1}} \tilde{A}\left(t-\tau\lceil K]\left\{u_{i}\right\} t d .(12)\right.
\end{aligned}
$$

The Newmark method is unconditionally stable if the coefficients of remainder terms are $\beta \geq 0.5, \alpha \geq 0, \mathbb{z}(\beta+0,5)^{2}$. Thus, the solution of integro-differential equations (7) with initial conditions (8) is as follows: 
A. Initial values are set: $\left\{u_{0}\right\},\left\{\dot{u}_{0}\right\},\left\{\ddot{u}_{0}\right\}=0$.

B. A system of algebraic equations (9) and (10) is formed, the right-hand side (11), (12) contains the terms describing viscous properties of material, depending on strained state of the system.

C. The resulting system of algebraic equations is solved by the Gauss method or the square root method.

A feature of the algorithm is that the integrals entering the expression (12) of the vector $\left\{W_{i+1}\right\}$ are calculated from the beginning of the process, while at each step the integrals are calculated in the range from $t_{i}$ to $t_{i+1}$. In this case, the total value $\left\{W_{i+1}\right\}$ at time $t_{i+1}$ is obtained by summing the value $\left\{W_{i}\right\}$ saved at the previous step and the integral obtained at the last stage with the integration limits from $t_{i}$ to $t_{i+1}$.

In concrete calculations, the Rzhanitsyn kernel [21] is used to describe viscoelastic properties of soil; viscoelastic parameters of soil are given in [22].

\section{Results}

The dynamics of the model of the Gissarak earth dam under the effect of various loads is investigated in this paper.

The Gissarak dam [17] has: geometrical dimensions $\left(H=138.5 \mathrm{~m}, \quad b_{\mathrm{gr}}=10.0 \mathrm{~m}, \quad m_{1}=2.2, m_{2}=1.9\right) ; \quad$ physical-mechanical characteristics of material of various sections are (for the dam core: $G=2780 \mathrm{kgf} / \mathrm{sm}^{2}, v=0.37, \gamma=0.0017 \mathrm{kgf} / \mathrm{sm}^{3}$; for the transition zone: $G=3500 \mathrm{kgf} / \mathrm{sm}^{2}, v=0.35, \gamma=0.00215 \mathrm{kgf} / \mathrm{sm}^{3}$; for retaining prisms: $G=3210 \mathrm{kgf} / \mathrm{sm}^{2}, v=0.30, \gamma=0.0019 \mathrm{kgf} / \mathrm{sm}^{3}$; for slopes strengthening: $G=8400 \mathrm{kgf} / \mathrm{sm}^{2}, \nu=0.25, \gamma=0.0024 \mathrm{kgf} / \mathrm{sm}^{3}$ ).

a)

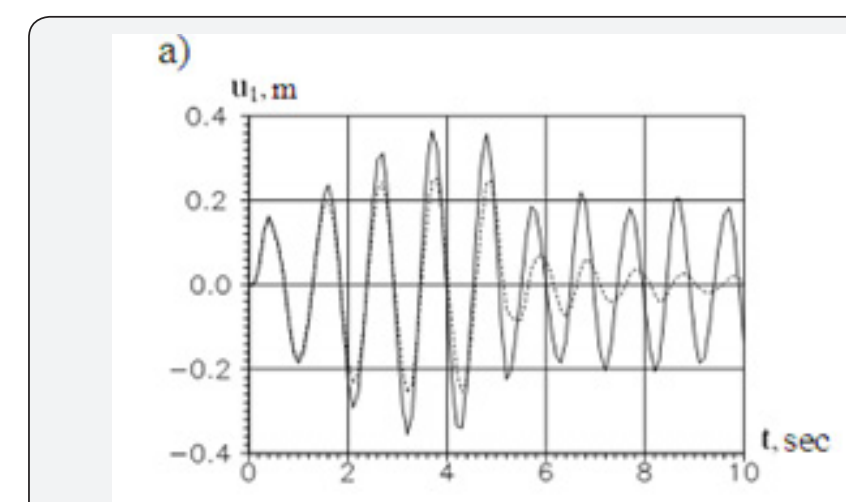

Here $H$ is the height of the dam; $b_{g r}$ is the width of the crest; $m_{1}, m_{2}$ are the coefficients of the rate of upstream and downstream slopes; $\gamma$ is the specific weight of material; $v$ is the Poisson's ratio; $G$ is the shear modulus of elasticity.

For a further study of structure dynamics, the kinematic effect at the base of the structure $S_{0}$ has the form

$$
\left\{u_{o}(t)\right\}= \begin{cases}a \sin (p) & 0 \prec t \leq t^{*} \\ 0, & t^{*} \succ t\end{cases}
$$

Here: $p$ - is the frequency; $a$ - is the amplitude; $t^{*}$ - is the time of the effect; $t$ - is the time of the process studied.

The displacements of various points of the dam in time have been determined under each effect using a spatial model. The parameters of the kinematic effect are taken as: $a=0.01 \mathrm{~m}, t^{*}=5$ seconds; $p=5.70 \mathrm{rad} / \mathrm{sec}$.

Figures 2-4 show the time variations of displacements of the point $\left(x_{1}=8 \mathrm{~m}, x_{2}=138.5 \mathrm{~m}, x_{3}=330 \mathrm{~m}\right)$ on the crest of the Gissarak dam, obtained with spatial model under one-component kinematic effects (different in directions) in the pre-resonant mode of oscillation. The solid line in Figure 2-4 corresponds to elastic solution, the dotted line is obtained taking into account viscoelastic properties of soil. Analysis of the results obtained shows that under one-component effect the displacements of the point in direction of the effect exceeds the displacements of the point in other directions by an order of magnitude (Figures 2-4). That is, one-component effect causes displacements of the model point, basically, only in the direction collinear with the effect; the remaining displacements (in orthogonal direction) are insignificant (Figure 2).

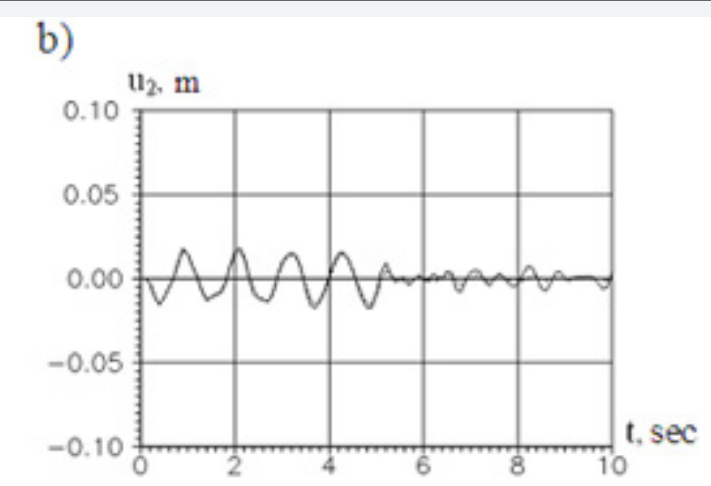

Figure 2: Oscillations of the Point $\left(x_{1}=8 m, x_{2}=138.5 m, x_{3}=330 m\right)$ of the Gissarak dam, obtained with spatial model under horizontal effect (i.e. in $\mathrm{u}_{1}$ direction).

Therefore, under horizontal effect (i.e. perpendicular to the longitudinal axis of the dam) the use of plane model in the assessment of dynamic behavior of a dam is justified, since in this case the components of the tensor of displacement in longitudinal direction to the dam plane, i.e. $u_{3}$ is less by an order of magnitude than $u_{1}$ and $u_{2}$.

Under vertical effect the tensor components of the displacements in transverse (horizontal) direction $u_{1}$ are by an order of magnitude less than $u_{2}$ and $u_{3}$, which are also orthogonal to the direction of the effect. Under such effect, it is advisable to use a spatial model, which allows to determine vertical displacements of points not only of the central cross section (as in plane model), but also vertical displacements of points of dam site.

Under longitudinal effect the tensor components of the displacements in transverse (horizontal) and vertical directions, i.e. $\mathrm{u}_{1}$ and $\mathrm{u}_{2}$ are by an order of magnitude less than $\mathrm{u}_{3}$ in longitudi- 


\section{Civil Engineering Research Journal}

nal direction. For the same reason, the spatial model can also be used when calculating a structure under longitudinal kinematic effect, which causes mainly longitudinal displacements of points (Figure 4). Analysis of the results obtained shows that viscoelastic properties of soil under load effect slightly reduce the amplitude of oscillations of the structure, and after effect cessation these properties lead to a sharp attenuation of oscillations. When taking into account elastic properties of soil after effect cessation, the oscillations do not attenuate, and the structure oscillates with the amplitude reached at the time of effect cessation at fundamental natural mode of oscillations (Figure 2-4). a)

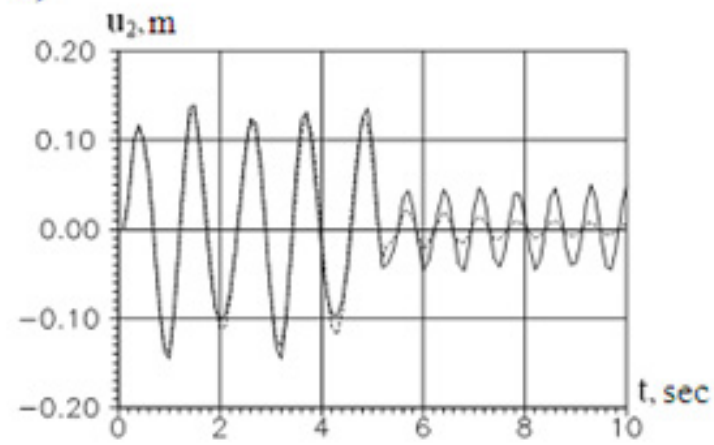

b)

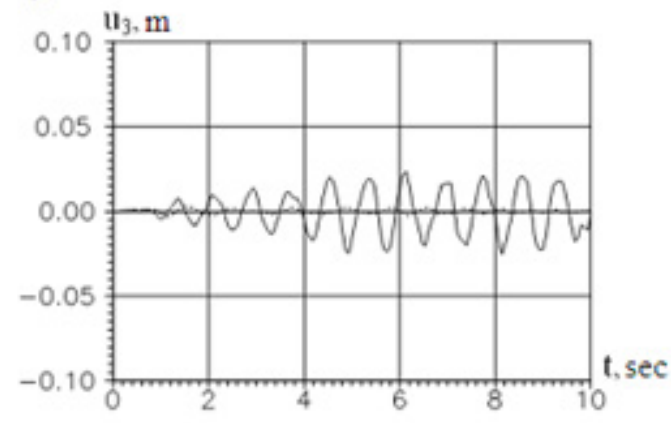

Figure 3: Oscillations of the Point $\left(x_{1}=8 m, x_{2}=138.5 m, x_{3}=330 \mathrm{~m}\right)$ of the Gissarak Dam, Obtained with Spatial Model under Vertical Effect (i.e. in $\mathrm{u}_{2}$ direction).

\section{a)}

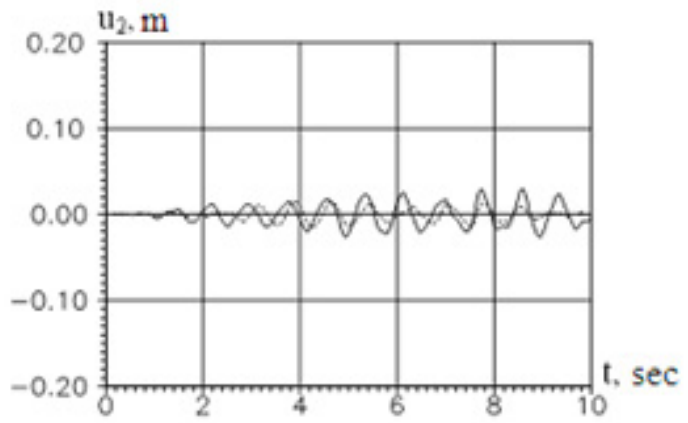

b)

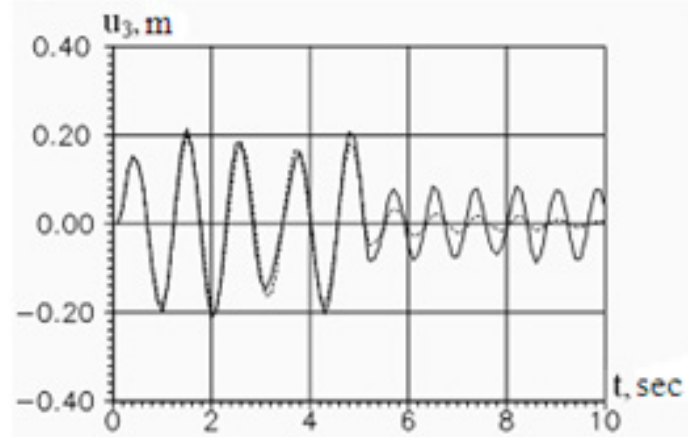

Figure 4: Oscillations of the Point $\left(x_{1}=8 m, x_{2}=138.5 m, x_{3}=330 m\right)$ of the Gissarak Dam, Obtained with Spatial Model under Longitudinal Effect (i.e. in $\mathrm{u}_{3}$ direction).

\section{Conclusion}

A. Methods and algorithms to study the dynamics of earth dams using a spatial model and taking into account viscoelastic properties of soil under one-component kinematic effect are presented.

B. Analysis of dynamic behavior of the dam under consideration has shown that for a given dam under horizontal effect it is possible to use a plane computational model, but under other effects it is necessary to use a spatial model of a structure.

C. Viscoelastic properties of soil under the load lead to a slight decrease in the amplitude of oscillations, and after effect cessation, to a sharp attenuation of structure oscillations.

\section{References}

1. Krasnikov ND (1981) Seismic Stability of Hydro-technical Structures Made of Earth Material. Moscow, Energoizdat, Russia, p. 240.
2. Polyakov SV (1978) The Consequences of Strong Earthquakes. Moscow, Stroiizdat, Russia, p. 311.

3. Polyakov SV (1983) Earthquake-resistant Elements of the Structures Higher School, Moscow, Russia, p. 304.

4. Rasskazovsky VT, Rashidov TR, Abdurashidov KS (1967) The Consequences of the Tashkent Earthquake. Tashkent, Uzbekistan, p. 144 .

5. Shteinberg VV, Pletnev KT, Grizer VM (1977) Accelerograms of Ground Oscillations during the Devastating Gazli Earthquake on May 17, 1976. Seismic resistant construction 1: 45-61.

6. Housner GW (1955) Properties of Stround Motion Earthquakes. Bull of the Seismological Soc of America 45(3): 197-218.

7. Sultanov KS, Salyamova KD (2012) The Stress State of the Dam Taking into Account the Elastic-plastic Strains of Soil. Improving the Efficiency, Reliability and Safety of Hydraulic Structures. Proc. of the Republican Scientific Practical Conference, Tashkent, pp. 131-135.

8. Mirsaidov MM, Sultanov TZ, Khodzhaev DA (2012) Assessment of the Stress-Strain State of Earth Dams. Civil-Comp Press, Stirlingshire, UK, pp. 100-118. 


\section{Civil Engineering Research Journal}

9. Mirsaidov MM, Sultanov TZ (2014) Assessment of Stress-strain State of Earth Dams with Allowance for Non-linear Strain of Material and Large Strains. Magazine of Civil Engineering 5: 73-82.

10. Sultanov TZ, Khodzhaev DA, Mirsaidov MM (2014) The Assessment of Dynamic Behavior of Heterogeneous Systems Taking into Account Nonlinear Viscoelastic Properties of Soil. Magazine of Civil Engineering 1: 80-89.

11. Mirsaidov MM (2011) Seismic Stability of Different Earth Dams. 6th International Conference on Dam Engineering, LNEC, Lisbon, Portugal, pp. 787-798.

12. Sultanov TZ, Mirsaidov MM, Khodjaev DA (2012) Evaluation of Dynamic Behavior of Non-uniform Structures with Account of Non-linear and Viscous-elastic Characteristics of Material. Proc of Australasian Structural Engineering Conference, ASEC, Perth, Australia, p. 63-70.

13. Salyamova KD (2003) Dynamic Calculation of Soil Structures Taking into Account Non-linear Models of Soil under Seismic Effects. Uzbek Journal Problems of Mechanics 1: 32-35.

14. Barysheva NN, Seleznev GS (1978) Oscillations of Hydroelectric Plant of the Nurek dam during an Earthquake on July 30, 1974. Seismic Resistance of Dams 4: 126-134.

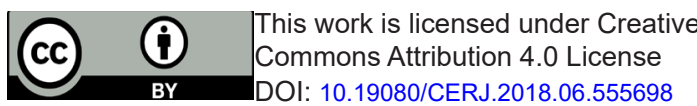

15. Sultanov TZ, Ishmatov AN, Yuldashev BSh (2017) Solving Problems of Nonlinear Oscillations for Earth Dams by Expanding into Own Modes of Vibrations. Irrigation and Land Melioration 2: 32-37.

16. Mirsaidov MM, Sultanov TZ, Abdikarimov RA, Ishmatov AN, Yuldoshev BSh, et al. (2018) Strength Parameters of Earth Dams under Various Dynamic Effects. Magazine of Civil Engineering 1: 101-111.

17. Mirsaidov MM, Sultanov TZ (2015) Theory and Methods of Strength Assessment of Earth Dams. Lambert Academic Publishing, Saarbrucken, Germany, p. 341.

18. Koltunov MA (1976) Creep and Relaxation. High School, Moscow, Russia, p. 1976.

19. Ilyushin AA, Pobedrya BE (1970) Fundamentals of Mathematical Theory of Thermo-viscoelasticity. Moscow, Nauka, p. 280.

20. Bathe K, Wilson E (1982) Numerical Methods of Analysis and FEM Moscow, Stroiizdat, p. 448.

21. Rzhanitsyn AR (1968) Theory of Creep. Moscow, Stroyizdat, p. 416.

22. Mirsaidov MM, Sultanov TZ (2013) Use of Linear Heredity Theory of Viscoelasticity for Dynamic Analysis of Earth Structures. Soil Mechanics \& Foundation Engineering 49(6): 250-256.

Your next submission with Juniper Publishers
will reach you the below assets
- Quality Editorial service
- Swift Peer Review
- Reprints availability
- E-prints Service
- Manuscript Podcast for convenient understanding
- Global attainment for your research
- Manuscript accessibility in different formats
( Pdf, E-pub, Full Text, Audio)
- Unceasing customer service
Track the below URL for one-step submission
https://juniperpublishers.com/online-submission.php

